\title{
EL LITORAL: ¿OBJETO DE CONSUMO O DE PLANIFICACIÓN? UNA COMPARACIÓN ENTRE CÓRCEGA Y BALEARES
}

\author{
Jean-Marie Furt \\ Université de Corse \\ furt@univ-corse.fr \\ Miguel Seguí Llinás \\ Universidad de las Islas Baleares \\ msegui@uib.es
}

\section{RESUMEN}

Córcega y las Baleares son espacios insulares próximos geográficamente, pero con un desarrollo turístico completamente distinto. Su diferente evolución a través de los años se debe a multitud de causas, tanto sociales, culturales como políticas y será a partir del segundo milenio cuando parecería que sus interrogantes convergen, pero será sólo en apariencia ya que sus bases sociales y económicas son totalmente distintas. La planificación llevada a cabo ha sido diametralmente opuesta y mientras en Córcega habrá que esperar el segundo milenio para que se materialice, en Baleares se lleva a cabo desde finales de los 80 . Actualmente, con la sostenibilidad, parece que ambas se encuentran frente a un cruce de caminos, pero no son los mismos caminos, la realidad tan distinta que viven hace que ni siquiera este concepto sea capaz de acercarlas y que sus intentos de aplicación sean distintos. La infraestructura empresarial y económica que viven y han conocido hace que su óptica del desarrollo, basado siempre en la utilización del litoral como recurso, sea divergente en todos los campos.

Palabras clave: Baleares, Córcega, planificación turística, litoral, sostenibilidad.

\section{ABSTRACT}

Corsica and the Balearics are near geographically, but with a completely different tourism development. Its different evolution through the years is due to many social, cultural and

Fecha de recepción: septiembre 2012.

Fecha de aceptación: mayo 2013. 
political factors, and will be starting the second millennium when it appears that their questions converge, but it will be only in appearance, because their social and economic bases are totally different. The planning has been carried out diametrically opposed, while in Corsica should expect until the second millennium to materialize it, in Balearic takes place from the late 80s. Currently, through sustainability, it seems that both are in front of a crossroads, but are not the same roads, the reality that they are living is so different, that makes this concept even not be able to bring them closer and that their attempts to apply are different. The business and economic infrastructure, that they are living and always have known, it makes your development perspective, always based on the use of the coast as a resource, is divergent in all fields.

Key words: Balearic Islands, Corsica, tourism planning, coastline, sustainability.

\section{INTRODUCCIÓN}

El Mediterráneo es uno de los principales destinos turísticos mundiales (Plan Bleu, 2005), con su oferta basada principalmente en el producto de «sol y playa». Esta atractividad del litoral, y especialmente del litoral insular (Bernardie Tahir, 2011), es el centro, a menudo, de un fuerte debate público que oscila entre la visión de su explotación y la tendencia a su protección (Duhamel y Violier, 2009). Córcega y las Baleares fueron dos destinos insulares que tuvieron que enfrentarse, casi al mismo tiempo, a la necesidad de llevar a cabo un desarrollo turístico y, por tanto, a utilizar los recursos de que disponían, que eran, básicamente, recursos naturales.

Pero, a pesar de esta coincidencia temporal en su origen turístico, el resultado ha sido completamente distinto, ya que mientras las Baleares evolucionaron hacia un desarrollo del turismo de masas y se optó por crear una oferta que respondiese a la demanda creciente que tuvo desde sus inicios; Córcega escogió un crecimiento limitado, respetuoso con sus tradiciones, cultura y organización social. A primera vista, parecería que las dos opciones obedecerían a dos filosofías distintas, donde, mientras que unos optaban por defender los paisajes vírgenes, conservar la naturaleza y respetar el litoral intacto, los otros se entregaban completamente a la acumulación de capital, al crecimiento económico, y eran indiferentes a su identidad cultural y a su pasado.

No han faltado en Córcega quienes han visto en este retraso en su desarrollo turístico una gran ventaja económica para la actualidad, frente, precisamente, a las nuevas demandas del mercado, ya que les da una oportunidad de poder vender el territorio que han sabido conservar de una manera distinta a como lo hicieron las Baleares, y aprovecharse de poder tener en estos momentos uno de los litorales mejor conservados del Mediterráneo. Se mire por donde se mire, todo parece indicar que en estos momentos en que Córcega está optando por escoger un desarrollo turístico, tiene todas las posibilidades ante este reto ya que, si aplicamos la teoría de Butler, se encontraría en sus inicios del desarrollo turístico y esto haría prever un crecimiento económico importante, mientras que las Baleares quedarían relegadas a la categoría de viejo destino turístico maduro con problemas de rejuvenecimiento.

La realidad, sin embargo, es mucho más compleja. Después de una ojeada a estos últimos cincuenta años, y, especialmente, a las medidas legislativas e iniciativas políticas de estos 
últimos treinta años, podremos observar que la evolución a partir de los años sesenta es consecuencia, en mucha mayor medida, de una historia económica y social bien distinta, más que de una diferente visión cultural e ideológica del litoral. En cambio, si nos centramos en estos dos últimos decenios, veremos que hay una aproximación entre la evolución de los dos espacios muy interesante.

Cada uno de los dos destinos encontrará en el concepto de sostenibilidad una ocasión para plantearse su futuro desde una perspectiva de renovar su oferta y ofrecer un producto completamente diferente, y lo están haciendo en un mundo que está avanzando irremediablemente hacia un sistema económico basado en una mercantilización constante de todo, entrando en el enfrentamiento entre sostenibilidad versus mercantilización, mientras que el litoral sigue siendo el objeto de deseo en cualquier política de desarrollo turístico. Curiosamente, intentaremos demostrar que, mientras en tiempos pasados el litoral ha motivado una línea de fracturas sociales y políticas, distinguiendo «los lazos que oprimen» y optando claramente por los «lazos que liberan» (Michea, 2007), nos encontramos actualmente frente a un simple proceso de una adaptación a la demanda. Veamos, simplemente, de una manera cronológica la evolución desde los años sesenta hasta la actualidad.

\section{II. ¿LITORAL CONTEMPLADO O LITORAL UTILIZADO?}

Multitud de autores (Urbain, 1999; Boyer, 2000; Duhamel, 2009, Vera, 2011) han analizado y descrito cómo se transforma el Mediterráneo en el gran destino turístico estival europeo y sus bases y explicaciones son bien conocidas, pero, sus inicios ya en los años 60 van a significar unas grandes diferencias entre las Baleares y Córcega. Mientras que para las Baleares será el inicio de un gran desarrollo y la creación de una verdadera «industria», para Córcega será el inicio de una etapa de incomprensión hacia él. Estas dos trayectorias tan diferentes han sido bien analizadas por varios autores locales (Seguí Llinás, 1995; Giudicci, 1997; Furt y Maupertius, 2006; Michaud, 2012) y será a través de estas visiones que intentaremos encontrar una explicación a estas trayectorias tan divergentes.

\subsection{Litoral contemplado}

El litoral como espacio contemplado será el caso de Córcega, que conoce a partir de la mitad de los 70 una reacción de desprecio y negación del turismo que se basará en principios de protección ambiental, especialmente del litoral. Bajo esta excusa de protección del medio ambiente se esconden muchos otros motivos, según los distintos grupos sociales, y un miedo a los cambios que se estaban produciendo en el mundo. Esta reacción es fruto de una cultura tercermundista y de una lucha ideológica y política contra las multinacionales, con el apoyo de una burguesía local que no quiere perder el control que está ejerciendo. Entre todos van a presentar al turismo como una actividad que simboliza la destrucción del medio y una acción de servidumbre frente al extranjero. Estas ideas van a configurar durante mucho tiempo el motivo de una fuerte lucha política.

La sociedad corsa sigue teniendo un fuerte peso del espíritu de clan en estos momentos y éste se esfuerza en mantener su poder, limitando la economía local a la acogida de turistas (Levratto, 2001). La política se centra en ofrecer una vida segura a través de las subvenciones 
con fondos públicos y por esto va a recaer sobre ella la fuerte responsabilidad de haber impedido construir un futuro sobre bases sólidas (Giudicci, 1997; Andréani, 1999). Bastantes años después, con el paso atrás del Estado, los cada vez más difíciles créditos públicos y la angustia de un futuro nada esperanzador, pero también con la deriva mafiosa de algunos nacionalistas (Martinetti, 2007), van a crear las expectativas de una posible evolución de las cosas.

Durante el primer decenio de los años 2000 se ha visto un retroceso progresivo de algunos eslóganes reductores utilizados hasta entonces en contra del turismo, del tipo «el todo turismo», «la monoactividad turística» o de expresiones perniciosas que presentan al turismo como «un mal necesario», y no será hasta tiempos muy recientes en que éste ha sido presentado como motor de la economía (Furt y Maupertius, 2011). Todos estos elementos nos llevarán en la actualidad hacia un cierto consenso, aceptando que el turismo se ha transformado en la principal actividad económica con sus tres millones de llegadas turísticas. Todo este proceso se ha ido plasmando estos últimos veinte años gracias a un fuerte compromiso hacia su desarrollo por parte de la Colectividad Territorial Corsa la cual, sobre un total de 60 millones de euros invertidos en ayudas al turismo, ella sola ha invertido 45 millones.

Todos estos cambios tan rápidos para intentar una recuperación económica se han basado principalmente en fomentar:

- El sector del alojamiento, en el que se aplica un esfuerzo importante que va a beneficiar a cerca del $45 \%$ de la oferta legal y va a provocar la construcción de 30 nuevos hoteles (1.200 camas), además de unos 300 apartamentos turísticos y la modernización (a través de un aumento obligatorio de la categoría) de más de 8.500 plazas.

- La náutica, ya que se la ha considerado como una rama prioritaria y que provocará la modernización del 80\% de los amarres de la isla y la creación de 3.000 plazas suplementarias. Aunque llama la atención que esto se produzca en una isla que basa su atractivo sobre la naturaleza y el paisaje y donde se conceden estos financiamientos sin contrapartidas «paisajísticas».

Aparte de la batalla medio ambiental que se prepara frente a estas medidas y las inquietudes que estos proyectos generan, especialmente con el precio inmobiliario, esta estrategia reduce la economía corsa a un modelo de simple acogida, ya que la gran mayoría de empresas locales, al no tener una masa crítica suficiente para entablar alianzas, se verán limitadas a recibir a los turistas y aceptar las rentabilidades que les ofrezcan los operadores turísticos del norte de Europa.

\subsection{Litoral utilizado}

Al contrario de Córcega, las Baleares han sido a lo largo de la segunda mitad del siglo $\mathrm{XX}$, el modelo de un destino de turismo de masas atraído por la naturaleza y el sol y playa. Esta imagen potente dura también durante el siglo XXI, pero su éxito es muy distinto del que hayan podido tener otros destinos mediterráneos. Sobre su superficie apenas superior a los $5.000 \mathrm{Km} 2$ y con una población de algo más de un millón cien mil habitantes, acoge más de doce millones de turistas. Este gran éxito tiene mucho que ver con la sociedad local que ha sabido aprovechar esta llegada masiva de turistas para elaborar su desarrollo, al principio conjuntamente con otros (operadores turísticos), pero luego ya de forma independiente. 
Desde el principio de la llegada del turismo de masas el archipiélago, en los años 60, esta sociedad se ha dirigido hacia la creación de servicios turísticos. Los inicios serán con acuerdos entre empresarios locales y operadores turísticos (ofreciendo la exclusividad de las plazas hoteleras al operador que financia la construcción de los hoteles). Gracias a esta fuerte relación, los hoteleros baleares van a transformarse en grandes especialistas de la gestión hotelera que será la base para el éxito de su expansión internacional. Este dominio de la gestión hotelera permitirá a lo largo de los años exportar sus conocimientos, primero hacia Canarias, luego al litoral mediterráneo, para dar el salto al Caribe, luego a América en general y ahora al resto del mundo, transformando estos pequeños empresarios en los propietarios de grandes cadenas hoteleras multinacionales.

Para conseguir este fuerte crecimiento y desarrollo ha sido necesario un doble consenso social. La población aceptó (no sin ciertos conflictos como nos narra Danielle Rozenberg (1990) que el turismo fuese el pilar del desarrollo económico insular. En segundo lugar, escogió invertir sobre el único recurso del que disponía (sol, clima, playas) aceptando la muralla de cemento y su cambio paisajístico en ciertos lugares a cambio de la creación de una herramienta industrial que impulsase el crecimiento. En Córcega, estas oportunidades no han existido y la oposición frontal a cierta actividad se ha traducido en la aparición de una «artesanía» a menudo predadora y la confiscación del crecimiento general de la isla en provecho de unos pocos.

\subsection{Caminos que han llevado a esta situación diferente}

Si damos una visión rápida a las dos evoluciones, nos plantearemos enseguida una pregunta: ¿cómo ha sido posible que una sociedad haya aceptado construir un muro de cemento en primera línea de mar para obtener riqueza de ello? ¿Por qué otras, en cambio, han defendido la virginidad de su naturaleza, aceptando por otra parte una cierta dependencia exterior?

La respuesta no es simple, como es de suponer, pero podríamos pensar en cuatro vías de aproximación:

- La primera, sería de orden económico, a partir de la teoría del consentimiento en pagar, y se basa en que una sociedad acepta sacrificar sus valores pasivos respecto a un bien ambiental (y especialmente el valor de transmisión de este bien a las generaciones futuras), esperando que este sacrificio se vea compensado por una riqueza futura. Esta teoría es fuertemente criticada cuando se aplica a grupos humanos grandes y a espacios importantes, basándose en el valor difícilmente cuantificable del consenso, que depende del sistema de gobernanza, y a su carácter evolutivo. Es por tanto, difícil de aplicar a largo plazo.

- La segunda se basa en las teorías actuales del paisaje y del patrimonio que los elevan a construcciones sociales (Donadieu, 2007) creando la voluntad de protección basada sobre el lado estético, relativamente contingente. Sería comprensible que si algunas playas, calas o puertos hubiesen sido construidos por Niemeyer, nos pondríamos de acuerdo para encontrar estas construcciones bonitas y, además, intentaríamos integrar este «cemento» tan criticado en un elemento patrimonial. La fragilidad de este argumento hará evolucionar las posiciones, ya que la defensa del paisaje se transformará a continuación en ecologismo, giro que será aprovechado 
por Córcega, y que luego se orientará hacia el desarrollo sostenible, aspecto que difícilmente cumple a no ser que nos limitemos a tomarlo como principio. Las Baleares también conocerán durante los ochenta este viraje hacia las luchas ecologistas, que se verán reflejadas en la Ley de Espacios Naturales (1991), pero que no serán impedimento para poner en marcha toda la batería de leyes que transformarán su realidad, tendiendo posteriormente también hacia una filosofía de sostenibilidad, que quedará siempre pendiente de alguno de los tres pies (social, ambiental o económico) (Seguí Llinás, 2003). De todos modos se ha pasado de los argumentos subjetivos y relativamente individualistas a discursos más científicos, normalmente más objetivos. Para Córcega, la tendencia hacia la sostenibilidad implica decisiones de la sociedad fundamentales, que tienen que ir más allá del turismo y que implican inversiones públicas muy importantes. También exigen cambios de actitudes individuales (circulación, tratamiento de residuos, gestión del agua...) incluso cambios en la sociedad (consumo) cuya ausencia en los planes regionales hace dudar de la seriedad de las propuestas.

- La tercera es más cultural. Carles Manera (2006) explica que el desarrollo turístico de las Baleares es fruto de su apertura, su relativa riqueza, pero también de su capacidad histórica de producir para vender, comerciar, negociar y servir de intermediario. Por tanto, la supuesta aptitud cultural de los mallorquines no sería más que el fruto de una larga historia que ha faltado a los empresarios corsos. «El espíritu de empresa no es ni una ciencia ni un arte, sino una práctica», decía Peter Drucker, es lo que ha faltado de manera continua y colectiva en Córcega impidiendo la posibilidad de construir una economía de servicios, ya que el desarrollo de una industria turística no se puede concebir a escala de un territorio sin un mínimo de cultura industrial y ésta inició su declive en Córcega a partir de 1930, lo que explicaría la situación actual. La cultura de la producción y del trabajo, omnipresente en Baleares, asociada al mito del progreso, lleva a una utilización de los recursos disponibles, pero también a su conservación cuando entran en peligro de desaparición y que no hay solución alternativa.

- La cuarta haría referencia a la situación en que se encontraban ambos territorios en el momento del inicio del turismo de masas. Así, las Baleares, vivían en una situación de pobreza en los años 50, como consecuencia de la Guerra Civil y la posterior II Guerra Mundial, lo que facilitó el hecho de que la población local vio en el turismo la herramienta que podía hacer posible salir del atraso económico en el que se vivía y, por ello, lo acogió plenamente, sin plantearse en ningún momento una planificación o un control sobre esta llegada de turistas, más bien al contrario, una predisposición total a su venida para provocar una modernización y el progreso económico de las islas. Mientras, en Córcega, en estos momentos se vivía el crecimiento económico que tuvo lugar en Europa al terminar la II Guerra Mundial y se recibían ayudas y subvenciones procedentes del Gobierno central que no hacían de la acogida de turistas una exigencia para poder salir adelante. Las Baleares no podían esperar nada de Madrid y esto, junto a su espíritu emprendedor, las volcó hacia el turismo, mientras que Córcega recibía muchas ayudas de París y podía seguir confiando en recibirlas.

Este repaso rápido de las cosas nos recuerda que los actores públicos van a intervenir progresivamente para construir una oferta que se corresponda con la demanda, interesada 
principalmente por un producto balneario. Nos encontraremos, por tanto, frente a una necesidad de entendimiento entre la normativa legal, las exigencias de una sociedad que, superando el aspecto estético, se preocupa también por la ecología y el medio ambiente como el caballo de batalla en el litoral, intentando, a la vez, la integración de estos destinos en un mercado mundial.

\section{EL MOMENTO DE LOS GESTORES}

En el período comprendido entre 1990 y 2005, los actores públicos intentarán tanto en Córcega como en Baleares poner en marcha un programa que permita unir crecimiento y protección. En Baleares, este proceso se basará en la vía legislativa, con una intervención fuerte de la comunidad, que llegará hasta la ruptura entre el Gobierno Autónomo y los poderes económicos con la ecotasa. En Córcega se intentará un marco de acción, tanto contractual como normativo, poniendo en marcha un plan de desarrollo sostenible que terminará con un fracaso. Aparte de las problemáticas políticas, parece que la evolución empresarial que quiere desarrollar una parte de la colectividad chocan con los bloqueos corporativistas (Crozier y Friedberg, 1977).

\subsection{Un desarrollo turístico basado sobre la calidad del destino}

Después de un decenio dedicado a un aumento importante de la oferta, hay que constatar en Córcega una falta de profesionalización. Para algunos actores, el turismo se limita a un negocio de circunstancias, un añadido a una actividad principal que permite conservar o mejorar su nivel de vida. Para otros, es una actividad lucrativa, pero estacional. Con este perfil de empresarios ocasionales, éstos no son proclives a plantearse las cosas, a innovar o a organizarse. Estos comportamientos, a los que hay que añadir los problemas locales de transporte, contribuyen a un aumento de los precios y focalizan la oposición al turismo. Los políticos han comprendido esta situación y han intentado paliar estas insuficiencias intentando conducir la evolución.

Si algunos de estos intentos han sido éxitos totales, demostrando la capacidad de adaptación de los profesionales (ha sido el caso de la estructuración territorial y la red de oficinas de turismo, cuyos directores se han transformado, a la fuerza, en verdaderos gestores de los territorios). Otros, marcados por un desfase entre la política de comunicación y la realidad de las capacidades productivas, han terminado en fracaso, contribuyendo aún más al retraso económico de la isla. Analicemos lo que está pasando con el programa «qualité Corse» que es la operación más representativa de estas dificultades.

Esta estrategia está integrada en un plan nacional «qualité-tourisme» que era el resultado de un temor a «un mercado cada vez más competitivo, clientes de cada vez más exigentes y la preocupación por poner en marcha un desarrollo equilibrado» (Bergery, 2002), con lo que el enfoque tampoco era muy innovador. Se trataba de crear una marca de referencia «qualité Corse» que implicaba un posicionamiento de marca turística y una adhesión de los actores locales. En el plano teórico, este análisis está basado en las nuevas reflexiones sobre el territorio (Gumuchian y Pecqueur, 2007). En el campo práctico, la misma fórmula ha sido utilizada en otras regiones francesas con unos resultados mediocres, intentando en todos 
los casos implicar a la población en un proceso de desarrollo basado en una marca identitaria que inscribiese durante mucho tiempo al destino en el imaginario de los visitantes. La estrategia seguida por la Colectividad Territorial Córcega, puede explicarse en parte por el retroceso de la financiación a nivel nacional y el final del turismo como elemento central de los contratos-plan, pero, a pesar de ello, levanta una serie de interrogantes:

- ¿Qué hay que construir alrededor de esta noción, tanto en el plano material como inmaterial, para hacer de ella un factor de atractividad?

- ¿Qué supone esta idea como inversión, pero también como renuncia por parte de los actores del territorio?

En cuanto a la primera pregunta parece que es posible darle una respuesta, aunque sea parcial, en una campaña que va más lejos de la de un simple anunciante o de la puesta en marcha de una política clásica de calidad, ya que se esfuerza en dar al proyecto una dimensión política, intentando establecer un verdadero contrato entre los visitantes y la población. La etiqueta «qualité Corse» quiere expresar un medio ambiente preservado, estructuras a medida humana, e identificación del territorio como un destino con carácter. No se hace ninguna referencia al litoral (ya que sigue con su connotación negativa) y se quiere indicar que no es allí, en la costa, donde van a encontrar al verdadero corso, ya que es el lugar que van los turistas, no los viajeros. Pero esta voluntad tiene muchas probabilidades de chocar con la realidad económica y social, ya que, ¿cómo podemos imaginarnos una clientela turística diferente sin hacer una prioridad de la política del tratamiento de los residuos o del sistema de saneamiento? Por ejemplo, ¿cómo se quiere desarrollar un destino eco turístico sin construir una verdadera red de transportes públicos o disponer de establecimientos con una etiqueta europea en la materia?

Todas estas necesidades no son tenidas en cuenta en la campaña de «qualité Corse», sino que ésta se limita a poner de relieve la belleza de los lugares (especialmente litorales) y a apoyar esfuerzos individuales inconexos, antes que fijar acciones claras y una estrategia a medio plazo. Estas incoherencias, vistas desde una perspectiva económica, se explican por el juego institucional, que aísla la política turística de las demás, entregándola así a los errores burocráticos y partidistas, antes que integrarla en una dinámica de desarrollo global. De este modo se deja de lado, al menos por el momento, los mensajes inscritos en el programa «qualité Corse», en beneficio de las aplicaciones técnicas.

Haciendo esto, se pospone para un futuro la posibilidad de tener un verdadero debate y, por tanto, de tomar decisiones. Citemos un ejemplo, la necesidad que exige el programa «qualité Corse» de admitir solamente «estructuras de dimensión humana». Esto se inscribe claramente en una voluntad de privilegiar una relación directa con la clientela y, por tanto, de contribuir a la construcción de un «destino de carácter». Bajo esta visión, el programa expone la voluntad expresada de no destruir el medio ambiente con construcciones gigantescas. Pero este discurso, que concita la unión de todos, oculta todo planteo sobre la profesionalización de las actividades, sobre la capacidad de las pequeñas estructuras por ofrecer perspectivas de empleo u ofrecer carreras profesionales y, por tanto, de atraer un personal formado, capaz de dinamizar un sector y de apropiarse los resultados. Ahoga también todo análisis de la situación local. Se niega, por ejemplo, a escuchar las demandas de algunos operadores turísticos, exponiendo la necesidad de disponer de algunos establecimientos de gran capacidad para desarrollar algunos campos (turismo de negocios, de congresos) y poder alargar la estación. 
Cabría preguntarse si este rechazo no es fruto de un funcionamiento corporativista, por parte de unos hoteleros locales, producto de una actividad artesanal, y la mayor parte de ellos herederos de un empresariado ocasional, que dominan los circuitos de alojamiento y las redes de discusión. El objetivo sería ir poniendo barreras a la entrada del mercado y hacer del «lo pequeño es bello» el «non plus ultra» de la autenticidad y de la hospitalidad, perpetuando un dominio que frenaría las inversiones y enterraría toda idea de modernización y adaptación global a la evolución de la clientela.

No existe este tipo de bloqueo en las Baleares, donde el Gobierno Autónomo ha podido llevar adelante evoluciones estratégicas fundamentales en referencia directa al litoral, sin sacrificar por ello la adaptación al mercado.

\subsection{Un desarrollo turístico basado en la diversificación del producto y de la oferta}

El sistema turístico creado en las Baleares desde los inicios de los 60 benefició a toda la sociedad, creando empleo y riqueza. Estos empresarios, que se apoyan en una capacidad de producción importante, y controlan una gran parte de la cadena de valor, fueron capaces de crear un destino de turismo de masas (del millón de turistas de 1965 a los casi 13 millones de 2013). La fuerte coherencia de la organización productiva que se puso en marcha permitió reaccionar a la crisis estructural de los años 1989-93 (Seguí Llinás, 1995) aceptando un encuadre legislativo hasta entonces poco implícito. Los poderes públicos, de acuerdo con los operadores, van a contribuir a reorganizar el producto para adaptarlo a las evoluciones de la demanda. Esta planificación territorial se orientará sobre dos ejes:

Por una parte, contribuir al cambio de imagen del producto para darle una fuerte connotación medio ambiental con el fin de atraer nuevas clientelas. Esta estrategia se tradujo, en el plan urbanístico, por la destrucción de construcciones hoteleras, una limitación a nuevas construcciones y por la multiplicación de espacios protegidos. Esta política se complementó con una fuerte inversión en las nuevas escuelas de Hotelería y de Turismo para acompañar así a las empresas en la búsqueda de un producto de calidad, fomentando la profesionalización.

Por otra parte, la diversificación de los productos turísticos se va a realizar implicando en el desarrollo turístico el interior de las islas, y, principalmente la montaña mallorquina que se transformará en el otro gran polo de atracción, además del litoral.

Pero si estas evoluciones demuestran la capacidad de adaptación de todos los actores del destino, por otro lado, no hacen más que difuminar la imagen que los turistas pueden tener de las Baleares, manteniendo intacto el peso del turismo balneario y la atractividad del litoral. Además, estas medidas contribuyeron fuertemente al fenómeno de las residencias secundarias que aparecieron con fuerza a partir de 1990. Esta explosión de las residencias secundarias será consecuencia de la limitación del crecimiento hotelero, así como del desarrollo del transporte (especialmente el aéreo, y más concretamente con la creación de un «hub» en el aeropuerto de Palma por la compañía Air Berlín) y por la aparición de nuevas formas de trabajo, gracias a las nuevas tecnologías (Porcel, 1998; Viard, 2006). Todo este proceso será el problema más grave durante el siglo XXI. En el plano de la conservación del territorio, la proliferación de residencias secundarias y el proceso de urbanización que conlleva, va a romper el equilibrio alcanzado con la legislación de principios de los 90 (pues ya no es solamente el litoral el que se ve atacado por las urbanizaciones, sino también las zonas situadas 
más al interior) y éste fenómeno residencial no será compensado psicológicamente entre la población con la creación de nuevos puestos de trabajo y la difusión de la riqueza entre la sociedad, ya que las residencias secundarias originan muy pocos puestos de trabajo y tienen poco impacto en la oferta complementaria.

En el plano político y social, además, la sociedad que había conseguido integrar hasta entonces la llegada de inmigrantes, se encuentra a partir de finales de los 90 con la dificultad de gestionar una población tan heterogénea de múltiples nacionalidades, del norte, del este y del sur, producto de una fuerte inmigración y de los «inicialmente» residentes de residencias secundarias (transformados algunos ya en residentes permanentes) y el continuo crecimiento de la llegada de nuevas poblaciones. No olvidemos que en 2011, los extranjeros ya eran el 20 '18\% de la población total de Baleares.

Estos problemas siguen muy presentes, y aunque suscitan algunos movimientos de oposición, la sociedad se enfrenta a la necesidad del turismo como motor y confía en el crecimiento económico para encontrar una solución a sus problemas. El único punto de inflexión a esta antigua regla es, en la actualidad, tanto desde el punto de vista social como de una simple técnica de marketing, el encontrar los medios para que este crecimiento sea sostenible.

\section{3. ¿Qué podría explicar este acercamiento entre los dos casos estudiados?}

Estos dos destinos se van a encontrar en este período con la urgente necesidad de defender el litoral concebido y presentado como un espacio frágil, centro de atención y catalizador de todos los combates ambientales. En ambos casos, hemos visto que los actores públicos han iniciado estrategias de empresarios: el litoral sigue siendo el producto estrella a partir del cual se desarrollan las políticas de diversificación postfordistas. Aunque podemos constatar cierto paralelismo en los dos casos: necesidades comunes, métodos empleados u objetivos previstos (una mayor rentabilidad del destino, una voluntad de controlar mejor y de organizar el mercado), siguen existiendo las diferencias fundamentales anteriores.

En Córcega, para llevar a cabo esta política sigue faltando un verdadero Plan Territorial, integrando el turismo y la isla en una visión global de desarrollo económico. Lo podemos notar, básicamente, en dos niveles:

Para las empresas, en primer lugar, pues la ausencia de un control de los flujos y de la producción, las supedita a los vaivenes de un mercado que no controlan y que siempre viene determinado por la imagen de sol y playa. Faltos de una producción turística industrial, los mejor organizados deberán contentarse con vender las baratijas del producto. Intentarán de todos modos, apoyándose en una organización territorial de calidad, ofrecer una oferta más cultural e identitaria, para atraer una parte de la clientela que no ha venido, sin embargo, a buscar esto.

Para los residentes también, pues el desarrollo parece reservado a una pequeña parte de la población por la falta de una decisión política global y de una verdadera organización, lo que impide asegurar la adhesión de la gran mayoría. Existe, por tanto, una fractura entre la afirmación de algunos objetivos (crecimiento, desarrollo), la presión que esto genera sobre los recursos patrimoniales y el sentimiento de una parte de la población que no se siente partícipe directa de esta apuesta, esperando simplemente poder sacar algunas ventajas suplementarias. 
Por el contrario, las Baleares han implantado desde hace tiempo un marco de crecimiento y, lo que hay que resaltar es que el sistema de gestión implantado permite, a nivel de una empresa, pasar de una especialización a una diversificación de su producto. Lo que de por sí ya es difícil en una empresa y no siempre es bien asimilado, parece relativamente exitoso a la escala de un territorio, aunque no hay que olvidar que, a medio y largo plazo, el sistema se vuelve difícil de gestionar. No debemos olvidar que estas evoluciones suponen una mayor apertura que hace más frágil la cohesión social que ha permitido este crecimiento y estos cambios.

Los dos territorios parecen encontrarse en la actualidad frente a un cruce de caminos, pero, a primera vista, no son los mismos caminos.

\section{EL MOMENTO DE LAS DUDAS}

Si esta situación hecha de interrogantes, de efectos de anuncio y de retroceso, parece una continuidad en el tiempo para Córcega, es toda una novedad para las Baleares. En este momento de inseguridad, mientras la una intenta una diversificación que no quiere decirlo por su nombre, mezcla de géneros y de actores, que tiene la ventaja de no molestar a nadie pero que corre el riesgo de estropearlo todo, la otra busca ya la vía del post-turismo.

\subsection{Un litoral sin complejos}

El proyecto de Plan Territorial (PADDUC) hacía de la dualidad capital natural / patrimonio cultural «el principal vector de imagen exterior de Córcega, en una palabra, un motor de desarrollo sostenible, privilegiando la solidaridad intergeneracional». En materia turística proponía «el desarrollo de una imagen de destino eco turístico, promoviendo las inversiones, especialmente hoteleras, que aplicasen las buenas prácticas, promoviendo las propuestas de calidad, desarrollando proyectos que aporten flujos fuera del período estival (golf, puesta en forma, actividades al aire libre, deportes náuticos» (CTC, 2008). En estas breves frases podemos ver ya la ambigüedad o, quizás, la visión reductora de una noción, cuyos fundamentos son, sin embargo, reivindicados por muchos planes y estrategias de desarrollo. La naturaleza militante del desarrollo sostenible, «su voluntad de contribuir al desarrollo de la economía local, respetando el medio natural y cultural» queda completamente diluida en un posicionamiento eco turístico acompañado de una búsqueda de calidad, que parece más defendible económicamente, pero, sobre todo, que parece menos conflictiva.

La nueva mayoría que tomó el poder en marzo 2010, en vez de aplicar una gobernanza más participativa y un diálogo ampliado al conjunto de actores, se ha refugiado en un plan más timorato en su elección. De todos modos, se alinea con los precedentes. Sus primeras propuestas son esencialmente técnicas. No generan una verdadera innovación buscando desarrollar un turismo alternativo que permitiría a la vez, escapar de las ataduras del mercado y de construir una independencia económica. De todos modos, ¿sería esto posible?, seguramente no en las condiciones actuales. Los cambios anunciados se transforman entonces en un medio para recrear nuevos equilibrios satisfaciendo a otros grupos de presión, permitiendo así una nueva respiración del sistema:

- Esta aparece en cuanto a la comercialización de nuevos productos (deportes náuticos, senderismo,...) en la que la eterna cuestión de la transformación del territorio en destino 
de golf se limita a la creación de nuevos recorridos. La pregunta es, en esta voluntad de diversificación, que debe romper la estacionalidad, (Coll Ramis y Seguí Llinás, 2014) y proponer verdaderas perspectivas de profesionalización, ¿qué pasa con el litoral? A pesar de los anuncios de una voluntad de reequilibrar el territorio o de enfocar el litoral como una puerta de entrada hacia el interior, el sol y playa se transforma en un producto más entre tantos otros, completamente desculpabilizado, libre de toda connotación negativa: ya no se pone moreno al sol, se disfruta, se «cargan las pilas». Pero no podemos dejar de señalar que las Baleares tomaron ya esta vía a través del éxito que supone un cierto control de la producción y de la distribución y que el éxito de las tres últimas temporadas parece confirmar. Las apuestas ambientales o económicas en Córcega, o los problemas del empleo, son ocultados en provecho de un statu quo que apenas molesta y provoca la satisfacción de algunos hoteleros y políticos.

- La encontramos aún con más fuerza en el plano social, con la reaparición del concepto de turismo identitario que no tiene absolutamente en cuenta las realidades locales y la desertificación rural. En este caso el turismo es llamado en auxilio de una agricultura abandonada, organizando la supervivencia de una población considerada la guardiana de los valores tradicionales de solidaridad. En el mismo campo, la negativa a abrir el transporte a una competencia controlada, consolida unos bastiones sindicales en detrimento de los residentes.

- En el plano económico, también, los problemas de empleo son ocultados en provecho de un statu quo que no molesta y que es satisfactorio para algunos hoteleros y políticos.

- Finalmente, en el aspecto ambiental, se justifica la utilización del patrimonio natural con fines turísticos con una generalización de la implantación de tasas. La idea es seductora, aunque poco original, (Segui Llinás, 2000). Quizás permita involucrar a la población local en un apoyo al turismo, incluso de «justificarlo», cuando este turismo aporta una contrapartida financiera segura para el medio ambiente. Pero esta elección supondría, en primer lugar, que se habría alcanzado el máximo fiscal existente.

Podemos comprobar que estas preguntas, así como estos procesos de diversificación, retoman, con algunos años de retraso, el camino seguido por los mallorquines. Por esto, podríamos considerar, ocultando las cuestiones actuales, que hay un camino correcto en una trayectoria de crecimiento. Pero, estas evoluciones son criticables, aparte del hecho de que las teorías unívocas de desarrollo son cuestionadas desde hace tiempo. Estas políticas son llevadas a cabo por los poderes públicos en su totalidad y, por tanto, están sometidas a los vaivenes de la política, a los bloqueos financieros y, a menudo, muy desconectadas de las exigencias del mercado. Intentan reproducir un esquema sin reconstituir antes sus fundamentos. Mientras tanto, con el fondo de la crisis y el retroceso de las ayudas públicas, los cambios impulsados en Baleares inician un repliegue, con aires de reciclaje, sin ocultar una reflexión profunda sobre su inmediato futuro.

\subsection{A la búsqueda de nuevos recursos}

La política de diversificación iniciada en Baleares en los años 90 va a cambiar completamente el espacio, que hasta entonces había estado bien separado entre lugares turísticos y los «reservados» a la población local. La ampliación de las zonas de producción turística (mon- 
taña, lugares culturales,...) y el desarrollo de promociones anuales (noches del arte, noches blancas, compras,...) basadas casi siempre en la ciudad de Palma, van a acentuar la presión inmobiliaria y provocar en los residentes una sensación de frustración del que van a tener en cuenta muchas empresas en el desarrollo de sus nuevas acciones (ver referencias de Antoni Riera o Eugeni Aguiló).

Ciertos empresarios consideran que el crecimiento debe apoyarse en un regreso a las tradiciones y a la identidad, con la renovación de viejos edificios rurales para transformarlos en hoteles rurales y aumentando la categoría y los precios de estos tipos de establecimientos. Pero la mayoría de ellos se inclina por una reapropiación del litoral. Sobre este terreno y en función de su historia y del control de su capital, los distintos empresarios van a desarrollar estrategias diferentes:

- Las pequeñas cadenas hoteleras (de una veintena de hoteles) cuyo capital, generalmente, es controlado por familias mallorquinas, copian las antiguas fórmulas y se expanden por las Canarias y el Caribe.

- Las grandes cadenas hoteleras tradicionales (Sol-Melià, Barceló, Iberostar, Riu) van a iniciar a partir del año 2000 trabajos de renovación de sus hoteles de sol y playa e, incluso, algunos, como Sol-Melià, intentarán crear una nueva generación de «resorts» renovando e integrando algunos establecimientos de Magaluf.

- Los grandes grupos integrados (Globalia, Orizonia -en quiebra en 2013-) cuyo capital es variado y con integración de fondos de inversión, tienen una visión más utilitaria del litoral y de las inversiones turísticas. Evolucionan y cambian en función de la demanda, y esto se ve facilitado por su integración.

Cualquiera que sea el tamaño de estas empresas, nos encontramos con estrategias de retorno geográfico a las Baleares, con formas industrializadas también, pero con una reapropiación del litoral, bajo la forma de los resorts o de los hoteles temáticos. También es el modelo económico que cambia, ya que muchos operadores se liberan de sus inversiones inmobiliarias para transformarse en gestores y explotar así sus conocimientos y experiencia. Esta metamorfosis, nacida de los cambios en la industria turística, nos abre campos nuevos y nos plantea cuestiones más amplias, con un futuro, seguramente, prometedor.

\section{CONCLUSIÓN: «GENTES DE MAR Y GENTES DE TIERRA» (SEGUÍ LLINÀS, 1991)}

La estrategia que se ha llevado a cabo en Córcega en el último Plan, había ocultado completamente los impactos del turismo sobre los residentes, tanto en términos de calidad de vida como del reparto del valor añadido. Esta estrategia no se interesaba en las contrapartidas que debía aportar el turismo a los inconvenientes sociales y a la desestructuración cultural que la actividad provoca, cuando es el turismo que por la rapidez de cambios que origina, invita a las sociedades a salir de sus bloqueos y debería animarlas a reflexionar sobre aquellos valores fundamentales que hay que conservar y cuales se pueden abandonar o ser reemplazados por otros nuevos (Diamond, 2005). Esta reflexión apenas se está iniciando actualmente a través de la fiscalización del acceso a ciertos lugares. Esta medida es una opción defensiva, de un utilitarismo que tendrá como efecto encarecer el valor de los bienes o de facilitar una privatización disimulada. Cualquiera de ellas tiene efectos desastrosos tanto en el campo económico como social. Esta estrategia de pago por los bienes comunes es ampliamente 
aceptada, pero está muy lejos de constituir una verdadera alternativa a una demanda social más compleja, atravesada por deseos y envidias contradictorios. Las dudas actuales sobre la defensa del litoral y la utilización de su interior podrían constituir los términos de un nuevo contrato social. Éste no debería reducirse a un simple debate, entre turismo o pobreza, nueva versión de la dictadura del progreso, ni ocultar una reflexión sobre la riqueza (Meda, 2008) y la producción. Faltos de este contrato, la aceptación actual del turismo sería un mercado de trampas y el desarrollo que generaría se vería, seguramente, apropiado por una minoría que sumiría a Córcega en un mar de dudas. Pero el camino es aún largo para alcanzarlo.

Este tipo de debate sobre las condiciones del desarrollo hace tiempo que está superado en las Baleares. Mientras que en Córcega se sigue cuestionando su existencia, en las Baleares el tema versa simplemente sobre su forma y su evolución. Los defensores de un futuro turístico apuestan por la experiencia de los empresarios y las posibilidades que ofrece la riqueza creada para defender la continuación de la experiencia. Dentro de este esquema, el litoral renovado estará siempre en el centro del proceso. Estos partidarios del crecimiento turístico pueden apoyarse desde 2011 en el nuevo aumento de la llegada de turistas, y, por tanto, del crecimiento. Sin embargo, el temor a una volatilidad en un contorno internacional inseguro permite a los que apuestan por un desarrollo tecnológico afirmar su deseo de salir del turismo para entrar en un «crecimiento cuaternario». Se basaría en la innovación, y la alta tecnología y se aprovecharía de la calidad de vida, de las infraestructuras y de las redes de comunicación y de transporte, financiadas en su mayor parte por el turismo. Esta tendencia se apoya, entre otras, en la dinámica del Parc BIT y corresponde a una lógica de clusters o de polos de competitividad, especializados en la investigación y la ingeniería de servicios. En esta opción, el litoral cumple como elemento de decoración que contribuye simplemente a una atractividad global. Sería una ruptura para las Baleares, pero es una vía ya explorada en otros territorios. El capital social acumulado permite favorecer esta revolución. El peligro estaría en sufrir un consenso social más difícil de encontrar que anteriormente, ya que se desarrolla en un mundo más abierto y en una sociedad que no tiene ningún parecido a la de los años 60 .

\section{BIBLIOGRAFÍA}

ANDREANI, J.L. (1999): Comprendre la Corse. Paris. Gallimard

BERGERY, L. (2002): Qualité globale et tourisme. Paris. Economica.

BERNARDIE-TAHIR, N. (2011): L'usage de l'île. Paris. Petra.

BONNEMAISON, J. (1996) : Gens de la pirogue et gens de la terre. Paris. Orstom Éditions. BUTLER, R.W. (1980): «The concept of a tourist area cycle of evolution: implication for Management of rssources», The Canadian Geographer, $\mathrm{n}^{\circ} 1$.

CAMPOCASSO, P.J. (2004): «Essor et crise de l'industrie 1830-1960». En Atlas ethnohistorique de la Corse (Ravis-Giodani, G. Edit.). Paris. CTHS.

COLL RAMIS, M.A. y SEGUÍ LLINÁS, M. (2014): «El papel del clima en la estacionalidad turística y la configuración de productos turísticos emergentes. El caso de Mallorca», Cuadernos de Turismo, $\mathrm{n}^{\mathrm{o}} 33$.

COLLECTIVITÉ TERRITORIALE DE CORSE (C.T.C.) (2008) : Plan d'Aménagement et de Développement Durable de la Corse. Ajaccio. 
CROZIER, M. y FRIEDBERG, E. (1977) : L'acteur et le système. Paris. Folio.

DIAMOND, J. (2005): Effondrement. Comment les sociétés décident de leur disparition ou de leur survie. Paris. Gallimard.

DONADIEU, P. (2007) : «Du pittoresque au durable, les natures touristiques du paysage », Espaces, $\mathrm{n}^{\circ} 254$.

DRUCKER, P. (1985) : Les entrepreneurs. Paris. Hachette.

DUHAMEL, P. y VIOLIER, P. (2009): Tourisme et littoral: un enjeu du monde. Paris. Belin.

FURT, J.M. y MAUPERTUIS, M.A. (2006): «Le tourisme en Corse : retour sur une évolution naturelle», en La Corse et le tourisme : 1755-1960. Ajaccio. Musée de la Corse et Éditions Albiana.

FURT, J.M. y MAUPERTUIS, M.A. (2011) : «Les îles peuvent-elles être des modèles de tourisme durable ? Une analyse comparative des stratégies des acteurs publics et privés en Corse et aux Baléares », en Insularité et développement durable (Taglioni, F., Dir.). Montpellier. IRD Éditions.

FURT, J.M. y MICHEL F. (2006) : Tourismes et identités. Paris. L'Harmattan.

FURT, J.M. (2011) : «Le patrimoine alibi du développement touristique local », en Tourismes, patrimoines et mondialisation (MICHEL, F. y FURT, J.M., Dir.). Paris. L'Harmattan.

GIUDICCI, N. (1997) : Le crépuscule des corses. Paris. Grasset.

GUMUCHIAN, H. y PECQUEUR, B. (Dir.) (2007) : La ressource territoriale. Paris. Economica. LEVRATTO, N. (2001): Y a-t-il une vie après la rente ? Ajaccio. Albiana.

MANERA, C. (2006): La riqueza de Mallorca. Una historia económica. Palma. Lleonard Muntaner.

MARTINETTI, J. (2007): «Les tourments du tourisme sur l'île de beauté», Hérodote, $\mathrm{n}^{\circ} 127$. MEDA, D. (2008) : Au-delà du PIB ; pour une autre mesure de la richesse. Paris. Flammarion.

MICHAUD, Y. (2012): Ibiza mon amour. Paris. Nil.

MICHEA, J.C. (2007): L'empire du moindre mal. Essai sur la civilisation libérale. Paris. Climats.

MORETTI, J.L. (2006): «Histoire de la planification du tourisme en Corse », en La Corse et le tourisme : 1755-1960. Ajaccio. Musée de la Corse et Albiana.

PLAN BLEU (2005): Adapting to climate change in the water sector. Sophia-Antipolis.

PORCEL, B. (1998): Méditerranée. Tumultes de la houle. Arles. Babel.

RIERA FONT, A., AGUILÓ PÉREZ, E. y PEÑALVA RIPOLL, A. (Coord.) (2009): Libro Blanco del turismo en Baleares. Hacia una nueva cultura turística. Palma. Conselleria de Turisme.

ROZENBERG, D. (1990): Tourisme et utopie aux Baléares. Ibiza une île pour une autre vie. Paris. L'Harmattan.

SEGUÍ LLINAS, M. (2003): «De l'impact des politiques touristiques. L'exemple des Baléares». Espaces, n 336.

SEGUÍ LLINÁS, M. (2000): «Le tourisme durable est-il une utopie ? L'exemple du projet d'écotaxe aux Baléares », en Tourisme durable, Les Cahiers Espaces, nº 67.

SEGUÍ LLINÁS, M. (1995): Les nouvelles Baléares, la rénovation d'un espace touristique mythique. Paris. L'Harmattan.

SEGUÍ LLINÁS, M. (1992): El descubrimiento de las islas olvidadas. Las Baleares y Córcega vistas por los viajeros del siglo XIX. Palma. Alpha 3 Serveis Editorials. 
URBAIN, J.D. (1999): L'envie du monde. Paris. Bréal.

URBAIN, J.D. (2002): Sur la plage. Paris. Payot.

VERA REBOLLO, J.F. et al. (2011): Análisis territorial del turismo y Planificación de destinos turísticos. Valencia. Tirant lo Blanc.

VIARD, J. (2006): Eloge de la mobilité. Essai sur le capital temps libre et la valeur travail. Tour d'Aigues. L'Aube. 